
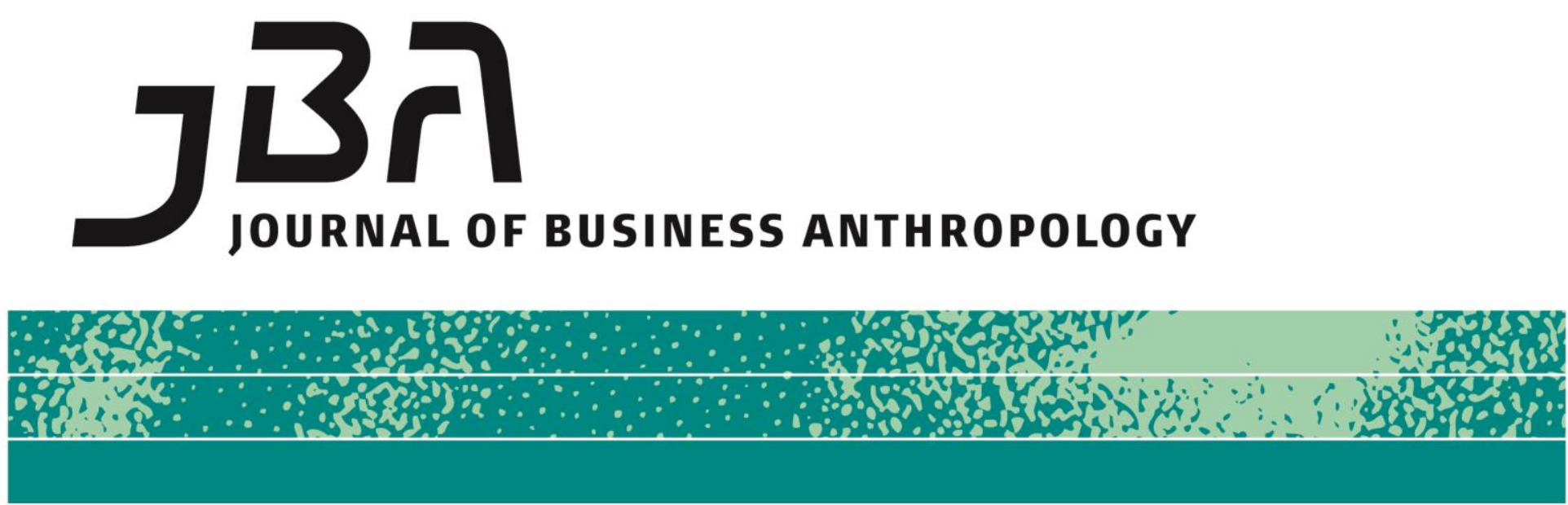

\title{
Business Ethnography: Inducing Liminality in Pursuit of Innovation
}

Patricia Wall and Jennifer Englert

\begin{abstract}
Ethnographic studies have become an integral part of many projects at Xerox: guiding product improvements, inspiring new product concepts, uncovering technology and organizational issues, and informing strategic directions. Ethnographic methods provide a deep understanding of technology usage in context and have the potential to shift the perspectives of the researchers themselves, the study participants, and the business stakeholders. These transformations facilitate the creation of innovative solutions that are meaningful and useful for the practitioners they are designed to support. In this article, we draw on three case studies to demonstrate how ethnographic methods invoke liminality, and how these studies support transformation in the perspectives of the researchers, practitioners, and stakeholders who participate in the studies.
\end{abstract}

\section{Keywords}

Ethnography, qualitative research, representations, transformation, liminality, innovation, future of work
Page 1 of 19

JBA Special Issue 2: 58-76, Spring 2016

(C) The Author(s) 2016 ISSN 2245-4217

www.cbs.dk/jba 


\section{Introduction}

Ethnographic practice at Xerox grew out of research efforts at the Palo Alto Research Center (PARC) in the late 1970s and early 1980s. Social scientists at PARC reached out to the product development and support arms of Xerox, which provided opportunities to study the use of emerging technology and its associated challenges in customer work places. These early exploratory efforts (Suchman 1987; Blomberg and Henderson 1990; Blomberg et al. 1996) highlighted mismatches between design intent (what technology was designed to do) and actual usage (how and why practitioners, or users, actually used the technology). They also provided insights and detailed descriptions of breakdowns between technology and practitioners, and gave technology developers the necessary information to re-evaluate their assumptions, and to develop strategies to design and implement improvements. In essence, ethnographic studies transformed the perspectives of technology designers in ways that allowed them to align design assumptions and implementations with actual practitioner needs.

These early ethnographic studies laid the foundation for an emergent practice at Xerox: that of involving social scientists in innovation and the design of technology to support better ways of working. Although practitioners had been observed and recorded many times before-in usability tests, customer site visits, and focus groups-none of these methods captured technology-in-use in the field, combined with the in-depth analysis and methods utilized by the social scientists.

Ethnographic methods have provided a deep understanding of technology usage in context and shifted the perspectives of everyone involved in the research. Ethnographers have played an important role in this shifting of perspectives by translating findings from the language and behaviors observed in the field, into implications and information that is usable by business stakeholders. Thus, ethnographers find themselves in a state of "tripartite liminality" (McCabe 2013:160) as they move "betwixt and between" (Turner 2007:95) the boundaries of parties such as researchers, customers, and product team members. Often, these studies have induced an unexpected liminal state for participants and business stakeholders, providing space for reflexive thinking, and therefore the transformation of their perspectives.

Rites of passage in business design and development projects: Inducing liminality

Anthropologist van Gennep describes three major phases inherent in individual and group transformations that take place during major life changes: separation (preliminal), transition (liminal), and incorporation (postliminal) (van Gennep 1960). These phases of transformation are not 
developed to the same extent in every situation. In the case of business ethnography studies, the phase of transition, or liminality, may be the phase that disrupts the status quo and invokes transformations in the world views of the researchers, practitioners, and developers who are involved. In fact, the ethnographic study itself may induce a state of liminality, providing the space and opportunity for reflection, and setting the stage for reflexivity and the co-construction of a new perspective or world view (McCabe 2013)

We find that ethnographic studies in the business setting can play a similar role to the rituals that support the transformational stages described by van Gennep. While business ethnography may not be conducted during stages of major life changes or crises, we see interesting similarities in the structure of the changes that its studies facilitate.

Ethnographic studies whose goal is to inform innovation tend to transform the world views, or perspectives, of all agents involved in the study-including ethnographic researchers, study participants, and business stakeholders. These transformations include the phases of separation, transition, and incorporation. For example, technology developers create technological solutions that embody their assumptions and perspectives-including how a particular solution will support a population of practitioners, and how that solution will be used. An ethnographic study of that solution in the context of use can shift the world view of the developers to align more closely with that of practitioners who are using the technology. It also can lead to the incorporation of refinements in the solution to support practitioners' work better.

Turner (2007:95) describes liminality as a state of being "betwixt and between." He states that liminality is "essentially unstructured (... at once destructured and prestructured)" (1967:98). The neophyte who enters the liminal state is structurally invisible, and has no place in the realm of culturally defined states. Turner and van Gennep discuss phases of transformation in the context of conscious rituals and ceremonies that are conducted to bridge between life stages. Moreover, they see liminality as a stage that happens within a single, serial process of transformation (van Gennep 1960). Initiates are conscious and aware of the transition process. However, in business ethnography studies, we suspect that participants, and sometimes business stakeholders, may not always be aware that a transformation might take place as the study progresses. Participants may not always recognize that they might enter into a liminal space in which reflexivity will change their world view about their own work and practices, or about how participants interpret and use the solutions they develop.

In studies at Xerox, both ethnographic researchers and study participants enter this state of liminality. As the study observations and interviews take place, they both step outside their everyday world to take 
a closer look at the activities and tasks that participants typically engage in during their everyday lives. This state of liminality also happens for technology developers during workshops and conversations which examine study findings and implications for the solution they have developed. It is the act of stepping outside of everyday tasks and assumptions to allow space for intentional reflection and reflexivity that transforms the world views of the people involved in the study.

In these cases, we see ethnographic methods as tools that induce a space of liminality and reflexivity, and therefore the co-construction of a new world view of participant practices. What follows is how those practitioners could be supported with technology or service offerings.

\section{Business ethnographers as translators of transformation}

Czarniawska and Mazza (2012) apply the concept of liminality to consulting. They suggest that consultants move in and out of liminal states as they engage with client organizations. These states of liminality can offer a sense of freedom, making room for creativity (Stoller 2009). Morais and Malefyt (2010:47) state that as business anthropologists "mediate between and among multiple cultures," it is essential for them to learn the language and culture of their corporate clients as well as of their informants. McCabe (2013) characterizes this mediation between cultures as a task that requires continual movement between the boundaries of clients and participants. She states that "business anthropologists move in such liminal space, regularly carrying out projects and communicating with people inhabiting different worlds of meaning" (p. 156). She describes this situation well: "In these situations, business anthropologists work in tripartite liminality as they move between the space of anthropological thought, consumer practices and client objectives" (p. 160).

This movement and translation between multiple interdisciplinary parties is very familiar to us. As business ethnographers, we find ourselves continually navigating between practitioners, customers, research teams, and other business stakeholders-developing a deep understanding of customer practices in one context and then transforming that understanding into formats that partners in research, product or services design can receive and make use of.

Liminality is traditionally seen as a stage that happens within a single, serial process of transformation (van Gennep 1960). However, we find that an iterative approach to transformation is a more effective way to make a lasting impact with business ethnography. The role of the ethnographer in a business context has to be fluid in order to enable multiple transitions and translations back and forth across boundaries, into customer environments and across relevant groups within his/her own organization. This iterative process, where ethnographers observe 
and invoke a reflexive self-examination in practitioners, translate insights from this process into implications for developers, and then use new questions or changes in tools from developers to refine or expand their observations of practitioners, leads to a resonance between practitioners and developers, which ultimately supports the development of tools or environments that better support practitioners and make the development process more efficient. This fluidity seems counterintuitive to traditional thinking on liminality, where the liminal phase, once passed through, is complete.

In this article, we present three recent case studies at Xerox that demonstrate how ethnographic methods induce liminality, and how this phase supports transformation in the world views and perspectives of the various people who participate in the studies. We describe how the studies invoked liminality; how ethnographers fluidly traversed the boundaries among project constituents; and how these studies impacted business strategies and solutions. The transformations and changes that occurred in these case studies had an iterative, fluid nature, which contrasts with traditional views of a more chronological version of liminality.

\section{Consumer research at Xerox}

Figure 1 illustrates our current view of the interplay of ethnographers, customers and product/services teams. Ethnographers are constantly negotiating an iterative, tripartite liminality as they navigate between the customers they study and the product/services teams they hope to inform. This is not an intermediary or gatekeeping role. Rather, ethnographers help translate and facilitate the co-construction of a resonant, integrated perspective between customers and developers, ultimately building mutual understandings, strengthening relationships and streamlining the path to effective innovation. We attempt to facilitate the integration of world views and perspectives in ways that help technology designers understand and support customers who will be using their solutions. 


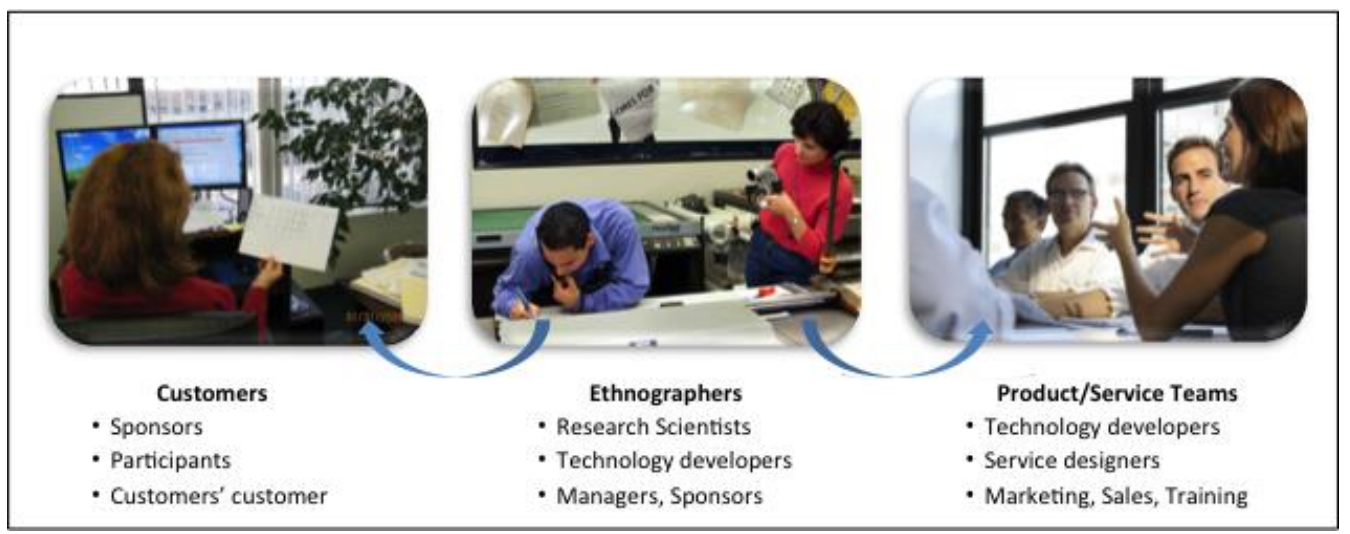

Figure 1: Interplay of ethnographers, customers, and product/service teams

Figure 2 illustrates the research methodology and the phases through which projects progress at Xerox. Field data are collected, analyzed, illustrated and shared with project constituents. Technology and services concepts and prototypes may be developed in design sessions with study participants. Iteration is possible at any stage in this methodology. For example, initial interviews and observations may result in a reassessment of study objectives or site selection. Due to the iterative nature of the methodology, it is not uncommon for one or more phases of a study to overlap. For example, ethnographers may find themselves analyzing data while still collecting data, or continuing data analysis while designing prototypes. These overlapping stages provide unique opportunities for researchers, participants, and stakeholders to enter into liminal phases where they step outside their daily routines, and can therefore facilitate changes in their perspectives. As translators between participants and business stakeholders, ethnographers traverse fluidly through multiple liminal states as the perspectives of participants and business stakeholders shift toward a closer alignment over time. 


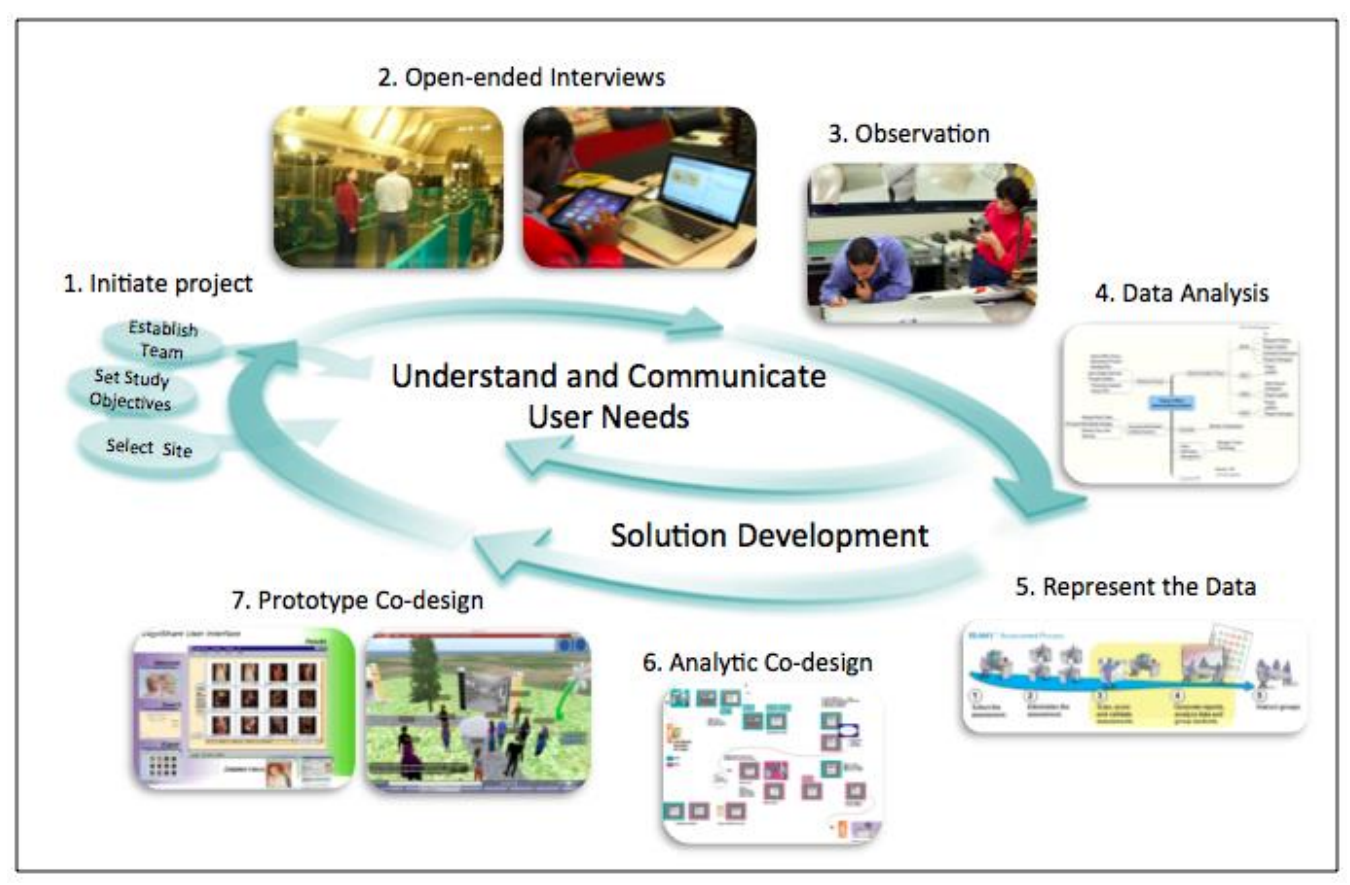

Figure 2: Research methodology

\section{Case 1: Re-focusing a technology development effort to support educators}

Our first case study illustrates how a research team redirected its efforts, based on an emerging view of customer work practices and needs. A study of primary school teachers was initiated to develop new software applications for an existing technology-multifunction devices that provide print, copy, scan, fax and network capabilities. This technology was already in use in many school districts. The research team was exploring opportunities for implementing new capabilities to make the technology more relevant and useful (Sprague and Fuhrmann 2013). Initial ideas proposed by the research team focused on providing customized course materials to support learning needs of individual students. When researchers and ethnographers began to observe teachers and school administrators, it became apparent that the educators had more immediate concerns. To personalize instruction, teachers were trying to manage a manual assessment process, which required them to conduct paper-based assessments, analyze results, and identify individual student needs. Teachers did not have the time to fully evaluate assessment results, let alone customize instruction according to student needs identified by the assessments.

Based on these observations, the research team redirected its development efforts to explore how it could help streamline the manual aspects of managing assessments, enabling teachers to focus on application of the assessment results in their daily interactions with students. The result of this re-focusing led to the design of a web-based teacher tool for printing, scanning, and automatically pre-scoring 
assessments that gave teachers rapid and valuable insights to help them customize instruction. This concept was evaluated and refined through iterative ethnographic studies, which observed the tool in use and gathered teacher feedback. As the tool was refined, further studies were conducted to tune the tool to better support the teacher's needs. The application has been commercialized and the researchers continue to collaborate with schools to define "what's next."

Initial field observations of educators invoked a state of liminality which allowed the research team to re-consider its assumptions that customized course materials would be useful for teachers. The team did not expect to reconsider these assumptions. The fieldwork helped it see that teachers' more immediate needs centered around the logistical nightmare of manually managing assets for large numbers of students. The research team, which included ethnographers and technology developers, iteratively traversed the boundaries between educators and developers to translate observations and discussions with educators into a new set of more relevant needs and requirements, thus enabling a transformation in their world views of what was possible. These new world views led to the development of a technology solution that supported teachers' immediate needs. This type of liminality did not arise from a serial, chronological process of transformation, as van Gennep (1960) describes, but rather was part of a process where the world views of the various parties engaged in the research (ethnographers, developers, and practitioners) became more attuned to one another, thus enabling the development of tools to better support practitioners.

\section{Case 2: Exploring 3D virtual museum spaces}

A project with an American history museum provides another interesting case for this article. It illustrates how ethnographers fluidly traverse the boundaries among the various parties involved in the project. It also demonstrates how ethnographic studies in the business context can invoke a state of liminality, providing an opportunity for research constituents to step outside their daily routines, shift their perspectives, and develop innovative solutions that support potential users.

\section{Background}

A Xerox research team struck up a relationship with an American history museum to explore topics of mutual interest. The museum staff was interested in making more of their 22 million artifacts available to the public. At the time of the study, the museum had only five percent of their holdings on display for public access. Museum staff were interested in growing the online collection, making images and information about artifacts available online, while also providing an environment for museum visitors to interact with one another and with the artifacts. 
The research team was interested in experimenting with digital collections and the potential application of virtual 3D environments to support interaction among people using collections. Based on mutual interests, the project took shape as a collaborative effort to design a prototype web-based environment to support visitor interactions with one another, the museum artifacts and museum staff (whether the visitors were onsite at the museum or elsewhere). Representatives from the museum staff (curators, directors and IT managers) and the corporate research team (ethnographers, computer scientists and user interface designers) made up the core team responsible for the project direction and deliverables.

Based on discussions with museum staff to define project objectives, ethnographers decided to focus their efforts on understanding visitor experiences and museum staff practices to support visitors. During the project, ethnographers were constantly finding ways to bridge the perspectives of all the project constituents-which included museum visitors, museum administrators and curators-and the research prototype developers, in order to inform the design and development of the prototype technology. Figure 3 illustrates the variety of interactions that unfolded throughout the study. These interactions induced a state of liminality, providing the opportunity for project constituents to step outside their everyday tasks, allowing space for reflection and reflexivity. Following are more detailed descriptions of the approaches used in the study, each providing an entry point into a state of liminality.

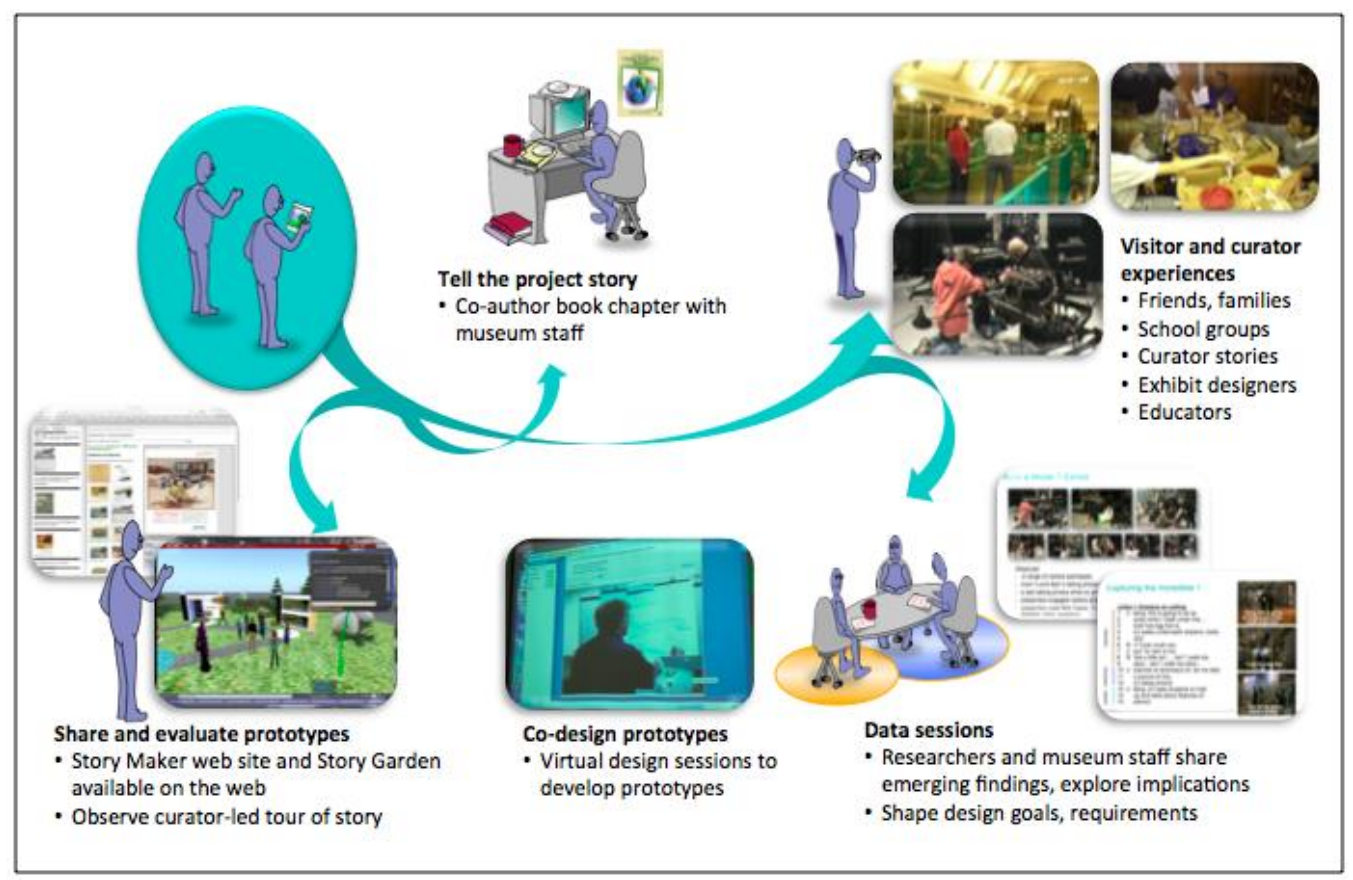

Figure 3: Traversing multiple boundaries: The museum project 


\section{Visitor and curator experiences}

Ethnographers interviewed museum staff, including curators, exhibit designers and educators, the people who regularly interact with visitors or design the exhibits (visitor experience). The team also shadowed and video-recorded a variety of visitors-including families, small groups of friends, and school groups-during their visit to the museum.

A key observation underscored the important role of stories in the museum visit. The curators used stories to inform the design of museum exhibits and to engage visitors. Visitors also used stories to make connections between the exhibits and their own personal experiences, sharing them with their companions. For example, parents enjoyed reminiscing with their children, inspired by artifacts such as cars, trains, toys or quilts. Several visitors documented aspects of their visit, taking photos with digital cameras or cell phones. The field study led to a better understanding of the ways visitors interacted with one another and with the exhibits, the technologies they used during the visit, and how they connected and made sense of the experience.

\section{Data analysis sessions}

Throughout the study, the ethnographers conducted iterative data sessions to share and discuss emerging findings with museum staff and explore implications for prototype design efforts with the prototype developers. These sessions provided opportunities for the ethnographers to refine their understanding of the goals and needs of the museum staff, and allowed technology developers to step outside their tasks of prototype coding and examine whether their design assumptions aligned with the goals and needs of the curators and visitors they intended to support.

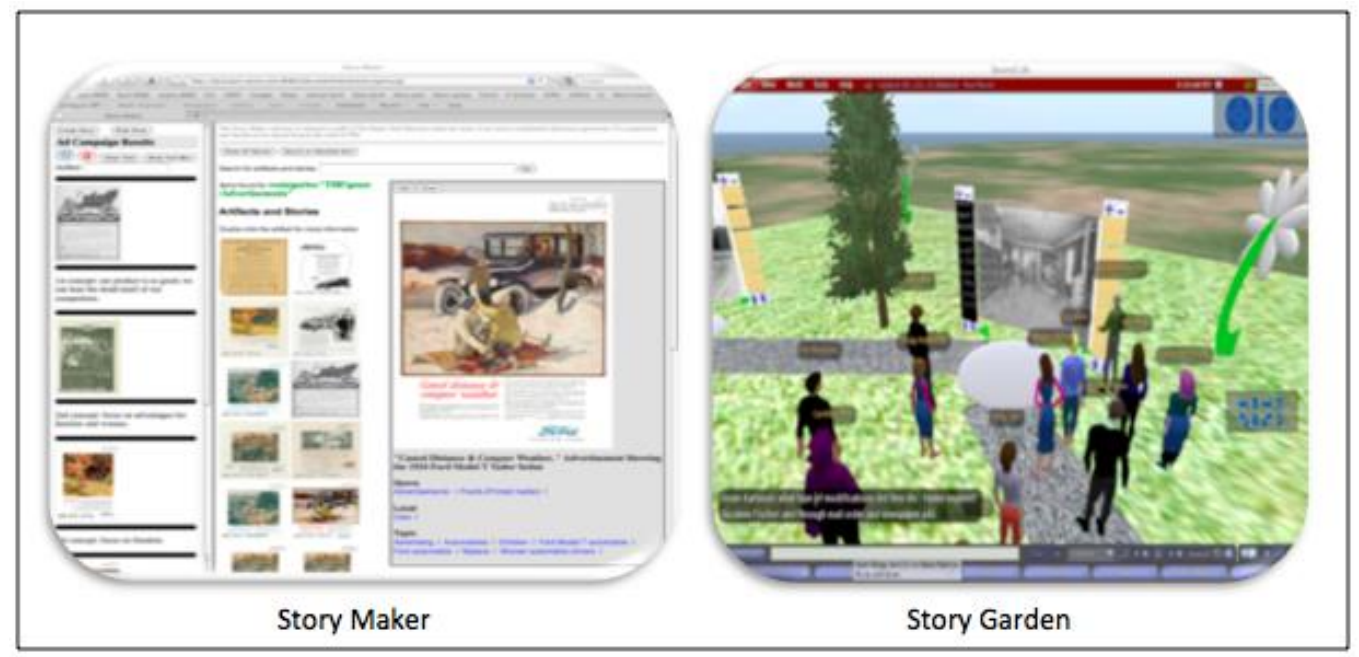

Figure 4: Museum project prototypes 


\section{Prototype design}

As prototype design and implementation got underway, the ethnographers organized weekly sessions with museum staff. These sessions facilitated the iterative refinement of design concepts, options and next steps as ethnographers fluidly traversed the boundaries between the developers and the intended users of their technology solution. This phase of the project took place over several months, during which two prototypes were developed, incorporating input from museum staff, ethnographers, and prototype developers. The final prototypes grew from conversations that were the basis for descriptions of the needs of museum staff and visitors. Prototypes were created and refined to address participant needs (see Figure 4).

One prototype was called Story Maker, which was a web-based story-building tool. Visitors could view images of artifacts via the web, make selections, and put them together to form a story that they could share electronically with friends and family. The other prototype, called Story Garden, was a 3D immersive environment for sharing stories that were created in Story Maker. Stories created in Story Maker could be imported and shared in the Story Garden where participants in the session, represented by avatars, interacted with each other through textbased comments and avatar gestures in the $3 \mathrm{D}$ space. ${ }^{1}$

\section{Prototype evaluation}

Museum curators evaluated the prototypes by creating stories using Story Maker and then sharing them with colleagues in the Story Garden. The story creation and storytelling experiences were recorded for subsequent analysis. The recordings provided a vehicle for discussions among the team (museum and research staff) to reflect on their experiences, envision prototype use in the museum and guide prototype refinements.

\section{Project story}

An unusual aspect of this project relative to other research projects was that the team of researchers and museum staff co-authored a chapter for a book, describing the project collaboration, methods and outcomes (Wall et al. 2012). Occurring at the conclusion of the project, the book chapter provided a vehicle for the collaborators to reflect on their efforts and cocreate a project artifact that summarized their collective experience and unique perspectives.

The museum collaboration illustrates how ethnographers fluidly traverse and bridge multiple boundaries throughout the course of an

\footnotetext{
${ }^{1}$ See Bier et al. (2011) for a more detailed description of the technology prototypes developed in this project.
} 
iterative research project. It also demonstrates how a study can invoke a space of liminality in which the shifting perspectives of research constituents can lead to innovative solutions. This example again demonstrates how the type of liminality we engage in is more fluid and less chronological than the version described by van Gennep (1960). While this project focused on exploring the development of a technology for creating and sharing artifact-enriched stories, the next example focuses on the exploration of emerging practices that impact business direction and strategy.

\section{Case 3: The Future of Work project}

The Future of Work is a third project highlighting how ethnographic studies can invoke liminality, and demonstrating techniques ethnographers can use to traverse the boundaries of multiple distinct perspectives.

\section{Background}

The Future of Work was a multi-year project looking at how work was changing as a result of emerging socio-technical trends-such as the use of smart phones, tablets, and cloud technology-and the consequent blurring of work and personal life. The research team described emerging work practices and discussed implications for Xerox products, services, solutions and strategy. As an exploratory project, it was not connected to a specific business group partner or technology development effort; instead, it was intended to inform many interested groups spread across the organization.

The project evolved over the course of five years, each year building on the results of the previous year, while adjusting the research questions to include emerging areas of interest (Watts-Perotti et al. 2009; Perotti et al. 2011). However, some of the study topics were explored each year, including:

- Where people do their work (e.g., mobile, remote, home, distributed)

- How they accomplish their work, coordination, interactions, tools

- How they manage information (or not)

- Balancing work life and non-work life

- Interplay of social and technical aspects of work life 


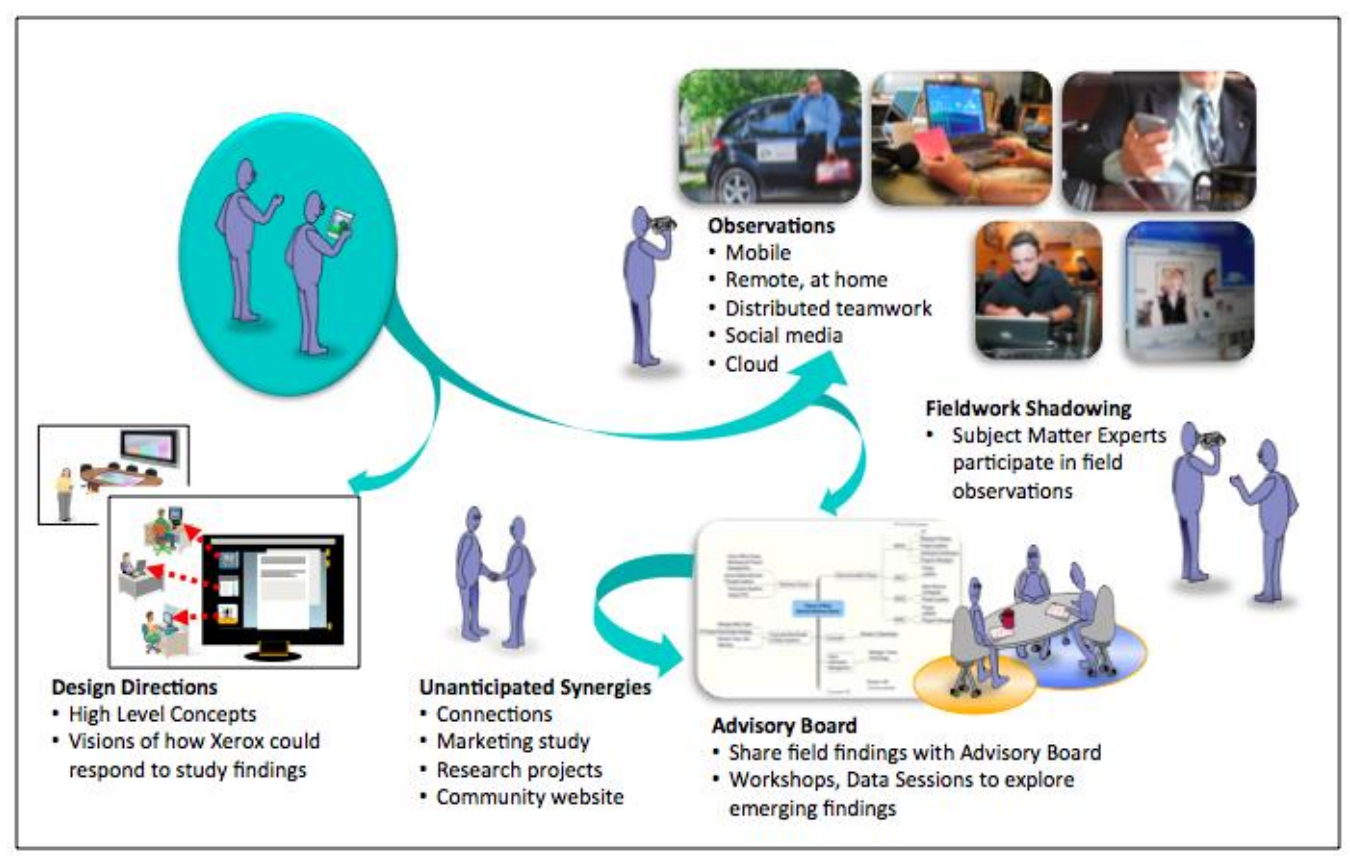

Figure 5: Traversing multiple boundaries: The future of work project

Study participants came from a variety of professions, selected for the study because they were experimenting with cutting edge work practices. Participants included people working from home or on the road, relying on places like coffee shops for office amenities like electricity, Wi-Fi access and of course, coffee. All participants used smart phones in combination with laptops (some had multiple cell phones and laptops). Many were trying to reduce their use of paper. The study included more than 100 participants over the course of the five-year project. They included small business owners, sales people, educators, consultants, and healthcare professionals.

Unlike the Museum project, business partners for the Future of Work project were a diverse, potentially unwieldy, group of individuals spread across several departments within Xerox. All of them brought different perspectives to the project, and all were interested in the study and the implications for their own distinct organizations. The research team used several techniques to traverse the boundaries of these internal groups and to translate study findings into formats that were useful for the each group (see Figure 5). Three of these techniques: the advisory board, fieldwork shadowing, and the development of a Design Directions Document are described below.

\section{Advisory board}

Since there wasn't a single sponsoring group to receive the study findings, the Future of Work team wanted to draw business group alliances into the project and formalize a way to share findings with these groups to increase the impact. They accomplished this by establishing an advisory 
board to anchor the research with practical business questions. Various business leaders who were responsible for planning and developing the next generation of product and service offerings were invited to participate as members of the board. These members contributed their perspectives and questions to the study and took project activities and findings back to their organizations. Interest and commitment for participation in the advisory board exceeded expectations. The advisory board ended up with more than 30 members representing fourteen groups across Xerox. The advisory board turned out to be mutually beneficial. Board member interests influenced the questions posed by the project, and in turn, the study resonated with board members, who brought findings back to their respective organizations and activities. The advisory board provided the opportunity for the project to influence many levels of the corporation in parallel, while providing an environment for the board members to make unanticipated connections and synergies among themselves (Watts-Perotti et al. 2009).

\section{Fieldwork shadowing}

Advisory board members and other subject matter experts (SMEs), such as from marketing and product development, were invited to accompany the Future of Work ethnographers into the field so they could experience the participants' worlds first hand. When SMEs were able to accompany the ethnographers, they had the opportunity to observe, help with the data collection (such as video camera support), and ask questions. Although they were not asked to analyze field data, they were expected to share their experience and impressions with the rest of the team.

This process of shadowing and sharing impressions often induced unexpected states of liminality for the SMEs. They discovered that watching cutting edge work practices first hand transformed their perspectives on how work could be done. Bringing SMEs into the field proved to be a positive and enlightening experience for both the ethnographers and the SMEs. This collaboration allowed the former to navigate between the perspectives of business stakeholders and study participants fluidly because when SMEs were in the field, ethnographers found it relatively easy to interpret and represent their interests. In addition, as the SMEs shared their field experiences with others in their own organizations, it seemed to "prime the pump," building interest for more detailed findings and discussion of implications in the context of their own work and objectives (Watts-Englert et al. 2016).

\section{Unanticipated synergies}

Putting a diverse set of people together around interesting research topics that are relevant to their work provides fertile ground for synergistic opportunities to emerge. Establishing the advisory board and 
inviting SME participation in the fieldwork resulted in many benefits as well as unanticipated synergies (Watts-Perotti et al. 2009, 2011). The Future of Work team was invited to participate in discussions with other Xerox organizations to share findings and implications. For example, meetings were organized by facilities and information technology (IT) organizations that were looking at ways to support the needs of an increasingly mobile, distributed workforce. The project also inspired a new IT research effort in collaboration with a sister research organization. These synergies and interactions continued to feed back into and shape Future of Work project directions and activities.

\section{Design directions document}

One of the main objectives of the Future of Work project was to describe the landscape of emerging work practices based on observations in the field. The data analysis resulted in the identification of several key themes. The researchers identified opportunities for new technologies or solutions that could facilitate existing practices or overcome a barrier that participants were facing. The team, including interested members of the advisory board, worked with designers to create sketches of concepts to describe these opportunities. Some of the concepts were developed as patents, and others were summarized in a design directions document, which explained the concepts in the context of the fieldwork themes and findings (Watts-Perotti et al. 2009, 2011). The design directions document provided a concrete way for ethnographers to translate the findings into a format that was usable for the development community.

The Future of Work project illustrates how ethnographic studies can invoke liminality in a business context, and offers new techniques ethnographers can use to traverse the boundaries of distinct parties involved in the research. The case study also shows how these techniques can enable translation and transformation of field experiences into mutual understandings that provide insights to impact strategy and future directions.

\section{Liminality in ethnographic work at Xerox}

In this article we have explored the concept of liminality as it relates to the work we do as ethnographers in a business context. Originally defined by van Gennep, liminality is the middle or transitory phase that takes place during major life changes. Our studies do not contribute to major chronological life changes, but instead facilitate innovation and the transformation of people, technology and practices in business settings, in a model similar to those of McCabe (2013), Field and Morgan-Klein (2010), Bruce et al. (2014), and Gibbons et al. (2014). These business ethnographic studies play a similar role to the rituals that support the transformational stages described by van Gennep. They invoke a space of 
liminality by inviting researchers, practitioners and developers to step outside their daily routines in order to examine their own work and consider how the work of practitioners can be better supported. This reflexive examination of practices and the development of tools to support them transform the world views of developers, leading to technology refinements, which then transform the world view and experiences of practitioners.

Ethnographers spend much of their time in a state of fluid liminality, as they translate insights from customer observations into implications for business professionals. A central role in this process for ethnographers is to build connections-with the customer and within their own organization-creating space for shared understandings, reflection and innovation. The transitional or liminal phase invoked by these studies sets the stage for change: the status quo is questioned, creativity may emerge, and new ideas can be co-constructed with study participants and developers. All those involved in the project-ethnographers, participants and business stakeholders-experience liminality.

While traditional descriptions of liminality see the phase as the crossing of a threshold, a point of no return-passed through once in the completion of a single, serial transformation (van Gennep 1960)-we find that an iterative approach to transformation is a more effective way to make an effective impact with business ethnography. Ethnographers at Xerox traverse multiple transitions and translations back and forth between customer environments and business groups within the company. This iterative approach increases resonance between business professionals, the customers they are supporting, and the technologies and services they are developing.

The projects we have described here illustrate different examples of the kinds of boundaries and liminal spaces ethnographers manage to accomplish their work. The museum project was motivated by an interest in making historical artifacts and stories about artifacts available to the public, and in providing a way for people to create their own meaning through stories. The project focused on innovation, inspired by current practice. The ethnographers built connections between museum staff and business stakeholders, and used iterative data sessions, technology evaluation sessions, and prototype design sessions to induce a space of fluid liminality where participants in the sessions could step outside their everyday tasks for reflection and creativity. The iterative combination and evolution of these activities supported the shift and integration of world views, guiding technology design. Ultimately, the technology prototypes and the project story that were co-created by museum staff, ethnographers, and prototype developers served as the tangible artifacts that embodied the new perspectives and transformations made by the team. 
The Future of Work project emphasized different techniques for inducing liminality. This project was based on an interest in understanding workplace trends and the implications for Xerox businesses. The ethnographers set the stage for uncovering insights about the changing landscape of workplaces by observing people experimenting with leading edge practices. The researchers found creative approaches to induce liminality, such as the advisory board, fieldwork shadowing with subject matter experts, and the creation of a Design Directions Document. All of these techniques helped the ethnographers create spaces for internal partners to step outside their everyday activities and think about how their projects might support new ways of working that had been enabled by new technology like smartphones and tablets.

To make an impact and inform innovation, business ethnographers must develop techniques like those discussed above: they must bridge the spaces between customer sites, research and various aspects of product/services development teams. They must make use of their unique set of skills and interests-creating a deep understanding of multiple points of view, and fluidly navigating across the borders of multiple perspectives. Their work opens up the opportunity for distinct groups to step outside their normal activities and co-construct new ways of working, supported by effective, innovative tools. When these techniques are used effectively, they provide the opportunity to reveal meaningful insights to guide positive, impactful change.

\section{References}

Bier, E., W. Janssen, P. Wall, J. Karlsson, T. Sun, W. Peng, and Z. Langford. 2011. A story-based approach to making sense of documents. IASTED Human Computer Interface Conference, Washington, DC, 15-18 May.

Blomberg, J. and A. Henderson. 1990. Reflections on participatory design: Lessons from the trillium experience. CHI 90 Proceedings of the SIGCHI Conference on Human Factors in Computing Systems, Seattle, WA, 1-5 April, 353-359.

Blomberg, J., L. Suchman, and R.H. Trigg. 1996. Reflections on a workoriented design project. Journal of Human Computer Interaction 11(3): 237-265.

Bruce, A., L. Shields, A. Molzahn, R. Beuthin, K. Schick-Makaroff, and S. Shermak. 2014. Stories of liminality: Living with life-threatening illness. Journal of Holistic Nursing 32(1): 35-43, March.

Czarniawska, B. and C. Mazza. 2012. Consultants and clients from constructivist perspectives, In The Oxford handbook of management consulting. M. Kipping and T. Clark, eds. Oxford, UK: Oxford University Press, 427-445. 
Field, K. and N. Morgan-Klein. 2010. Studenthood and identification: Higher education as a liminal transitional space. 40th Annual SCUTREA Conference, 6-8 July, University of Warwick, Coventry, UK.

Gibbons, S.W., A. Ross, and M. Bevans. 2014. Liminality as a conceptual frame for understanding the family caregiving rite of passage: an integrative view. Research in Nursing and Health 37(5): 423-36, October.

McCabe, M. 2013. 360 on method. Journal of Business Anthropology 2(2): 155-161, Fall.

Morais, R. and T. Malefyt. 2010. How anthropologists can succeed in business: Mediating multiple worlds of inquiry. International Journal of Business Anthropology 1(1): 45-56.

Perotti, J., M.A. Sprague, P. Wall, C. McCorkindale, L. Purvis, and G. McLaughlin. 2011. Exploring documents and the future of work. In Making work visible: Ethnographically grounded case studies of work practice. M.H. Szymanski and J. Whalen, eds. Cambridge, UK: Cambridge University Press, 109-127.

Sprague, M.A and M. Fuhrmann. 2013. Ethnography supports changes to student-centered instruction. The Qualitative Review $4^{\text {th }}$ Annual Conference, 18-19 January, Ft. Lauderdale, FL.

Stoller, P. 2009. The Power of the between: An anthropological odyssey. Chicago, IL: The University of Chicago Press.

Suchman, L.A. 1987. Plans and situated actions: The problem of human machine communication. Cambridge, UK: Cambridge University Press.

Turner, V. 1967. The forest of symbols: Aspects of Ndembu ritual. Ithaca, NY: Cornell University Press.

Turner, V. 2007. The ritual process: Structure and anti-structure. New Brunswick, NJ: Aldine Transaction.

van Gennep, Arnold. 1960. The rites of passage. M.B. Vizedom and G.L. Caffee, trans. Chicago, IL: University of Chicago Press.

Wall, P., J. Karlsson, Z. Langford, T. Sun, W. Peng, E. Bier, C. Overland, M. Butman, S. Fisher, and L. Korzetz. 2012. Guides and visitors: Capturing stories in virtual world and interactive web experiences. In Cases in online interview research. J. Salmons, ed. Thousand Oaks, CA: Sage Publications, 187-206.

Watts-Englert, J., M. Szymanski, P. Wall, and M.A. Sprague. 2016. Collaboration for impact: Involving stakeholders in ethnographic research. Collaborative ethnography in a business environment. M. McCabe, ed. Walnut Creek, CA: Left Coast Press, in press.

Watts-Perotti, J., M.A. Sprague, P. Swenton-Wall, C. McCorkindale, L. Purvis, and G. McLaughlin. 2011. Exploring documents and the future of work. In Making work visible: Ethnographically grounded case studies of 
work practice. M. Szymanski, ed. Cambridge, UK: Cambridge University Press, 109-127.

Watts-Perotti, J., Sprague, M.A., Wall, P., McCorkindale, C. 2009. Pushing new frontiers: Examining the future of paper and electronic documents. Ethnographic Praxis in Industry Conference Proceedings, September, Chicago, IL, 197-208.

Patricia Wall, M.S. is Manager, Work Practice \& Technology at PARC, A Xerox Company. She blends psychology, interaction design and ethnography to conduct socio-technical studies of people in a variety of contexts in order to design customer inspired technologies and services. She has extensive experience with participatory design approaches and creating visual representations of field study experiences. She manages a group of social scientists based in upstate New York. She has conducted ethnographic studies in a variety of settings including K-12 and higher education, digital libraries, government services, mobile and distributed work, call centers and healthcare. She is currently conducting ethnographic studies focused on patient experiences with healthcare. Patricia received a Master of Science degree in Psychology from North Carolina State University in Raleigh and a Bachelor of Science degree in Psychology from the State University of New York. She can be reached at Wall@PARC.com

Jennifer Englert, Ph.D. is a Senior Cognitive Engineer at PARC, A Xerox Company. For the last few years, has led a research initiative called the Future of Work-conducting ethnographic studies of mobile and remote workers to inform the development of future solutions and services at Xerox. Jennifer has also conducted fieldwork in the data analytics, customer care, healthcare, privacy, production printing and packaging domains. Dr. Englert earned her Bachelor of Arts degree in Psychology from Angelo State University, and her Masters and Ph.D. from The Ohio State University in Cognitive Engineering, where she held a 3-year National Science Foundation Fellowship. She holds sixteen patents in the areas of mobile devices, social networking, printing, digital media transfer, packaging, color management, and imaging. She is a recipient of the 2010 Xerox Excellence in Science and Technology award, and received the ASU presidential award upon graduating from Angelo State University. She can be reached at Jennifer.Englert@PARC.com 